\title{
Effect of minimum quantity lubrication strategies on tribological study of simulated machining operation
}

\author{
Sana Werda ${ }^{1, *}$, Arnaud Duchosal ${ }^{2}$, Guénhaël Le Quilliec ${ }^{2}$, Antoine Morandeau ${ }^{3}$, and René Leroy ${ }^{2}$ \\ ${ }^{1}$ Université Bordeaux, I2M, UMR 5295, 351 cours de la Libération, 33400 Talence, France \\ ${ }^{2}$ Université Tours, Université Orléans, INSA Centre Val de Loire, Laboratoire de Mécanique Gabriel Lamé Polytech Tours, \\ 7 avenue Marcel Dassault, 37200 Tours, France \\ ${ }^{3}$ Sandvik Coromant-CEROC, rue Henri Garih, 37230 Fondettes, France
}

Received: 3 April 2019 / Accepted: 26 September 2019

\begin{abstract}
The main aim of this paper was to reproduce the frictional behaviour that occurred in milling with a pin-on-cylinder system. Three different tribological tests were conducted reproducing friction phenomenon that happened in three machining conditions: (i) dry rubbing, representing the dry machining condition, (ii) MQL applied to front face rubbing which was similar to milling with MQL applied on the insert rake face and (iii) MQL applied to rear end rubbing which was similar to milling with MQL applied on flank face. Tribological tests were carried out with coated tungsten carbide pins rubbing on X100CrMoV5 steel cylinder. Apparent coefficient of friction, adhesion area and heat flux transmitted to the pin were analysed. It has been shown that MQL rear end rubbing provided a lower adhesion area and lower apparent coefficient of friction than with MQL front face rubbing. Furthermore, MQL rear end rubbing resulted in a greater cooling ability. These findings helped to explain why better results were obtained with MQL flank face lubrication in milling compared to MQL rake face lubrication.
\end{abstract}

Keywords: Minimum quantity lubrication / pin on cylinder / friction / adhesion / heat flux

\section{Introduction}

Minimum Quantity Lubrication (MQL) was an environment-friendly and economically beneficial method in machining [1-3]. Small amount of bio-degradable oil mist was sprayed on the cutting zone with pressurized air in order to improve machinability [4-6]. The extreme reduction in lubricant quantities resulted in nearly dry workpieces and chips. Several studies highlighted the benefit of using inner channels in order to specifically spray the cutting area [1,6-10]. This novel technique ensured precise lubrication supply directly to the cutting zone [11]. The difficulty for the oil mist to reach the cutting edges during machining was the main problem of this technique. The chip formation and the extreme contact between tool and workpiece limited the lubrication process [12-14]. In this context, a new spray method able to successfully lubricate the cutting edges needed to be considered.

Some authors have turned to insert flank face lubrication and compared it to conventional rake face lubrication. Masoudi et al. investigated the influence of

\footnotetext{
* e-mail: sana.werda@u-bordeaux.fr
}

MQL nozzle position on cutting forces and surface roughness during turning of AISI 1045 steel. The rake face sprayed by MQL nozzle gave lower cutting forces and lower roughness than a single nozzle on the flank face [15]. On another side, Ekinovic et al. investigated the influence of MQL rake face and flank face separately. Both lubrication methods gave the same results in terms of cutting forces. As a result, the position of the nozzle does not significantly affect the cutting forces during MQL turning of carbon steel St52-3 [16]. However, another study compared the influence of either simultaneously lubricating both faces, or solely on the flank face or rake face in finish turning of AISI 1045 steel with high pressure coolant. The longest tool lives were obtained when fluid was applied on the flank face with high pressure and low flow rate, or on both faces simultaneously with high pressure and high flow rate [17]. Banerjee et al. investigated an experimental system in end-milling Ti-6Al-4V wherein two separate supply systems provide an oil-air mixture at the rake and flank faces. The flow parameters such as proportion of oil are individually controlled at the rake and flank faces individually. It was found that injecting the oil fully at the flank face is beneficial for providing the best surface finish and decreasing tool wear [3]. Furthermore, Attanasio et al. 
compared dry machining with only rake face and flank face MQL lubrication during turning $100 \mathrm{Cr} 6$ steel [18]. Dry and MQL cutting with rake face lubrication presented similar tool life. However, whatever the tested feed rate, better tool life up to $20 \%$ was obtained with MQL applied on flank face. Moreover, after SEM analysis of the inserts, lubricant components were observed on the flank face (calcium and sulphide), but no chemical components of the lubricant were detected on the rake face. Furthermore, the study of Hadad et al. led to surface roughness decrease up to $15 \%$ when turning AISI 4140 steel with MQL flank face lubrication compared to rake face lubrication [19]. Finally, in a turning study of SCM440H, the surface roughness of the workpiece was improved by the oil mist supplied to the flank face over a large cutting speed range of 30-300 $\mathrm{m} \mathrm{min}^{-1}$ compared to rake face lubrication [20]. Recently, in previous experiments [21], the influence of MQL lubrication position in milling X100CrMoV5 steel has been investigated. Results showed that the efficiency of MQL process was ensured when applied to flank face. The lubricant penetrated the tool/workpiece interface which led to a lower surface roughness of about $40 \%$ and better tool life of $10 \%$ compared to MQL applied on rake face [21]. From the above studies, flank face lubrication is generally a better choice than rake face lubrication in turning and in milling. Nevertheless, there is an important lack of fundamental understanding of the phenomena occurring at the tool-chip and at the tool-workpiece interfaces [22]. In order to understand the wear mechanisms and such different behaviours when MQL was applied on rake face and flank face, tribological tests need to be considered. Hence, a tribological study was represented in this article to determine frictional behaviour regarding milling strategy to investigate the results in the previous study [21]. Two types of tribometers can be used: closed tribometers and opened tribometers. Closed tribometers processes consisted on a pin with a flat or spherical tip in friction against a disc, a cylinder or a plate. The pin rubbed continuously on the same track in order to determine the wear mechanisms of the pin. But, this pin-on-disc process did not consider a new rubbing friction surface occurred in milling machining $[23,24]$. In order to represent the real frictional contact during milling, opened tribometers were used to offer better similarity with machining since pins were rubbed over a constantly new surface.

The opened systems of Zemzemi (axial tribometer) and Bonnet (radial tribometer) were therefore found to be effective in simulating the tribological conditions similar to those occurring at the tool-chip and tool-material interfaces. Both of these tribometers reached a contact pressure of $3 \mathrm{GPa}[23,24]$. The results obtained with the Bonnet's tribometer showed coherent results in terms of apparent coefficient of friction. More specifically, results with MQL showed lower coefficient compared to dry tests $[14,25,26]$. Moreover, this tribometer provided the opportunity for a wide range of rubbing speeds [24]. From these previous results, the choice focused on the tribometer type of Bonnet and the tribological study presented in this paper was investigated with radial pin-on-cylinder tests.

The main aim of this article was to investigate two MQL conditions (Flank Face and Rake Face lubrication)

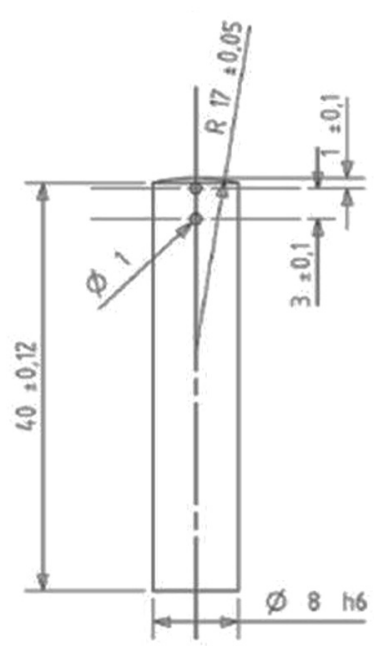

(a)

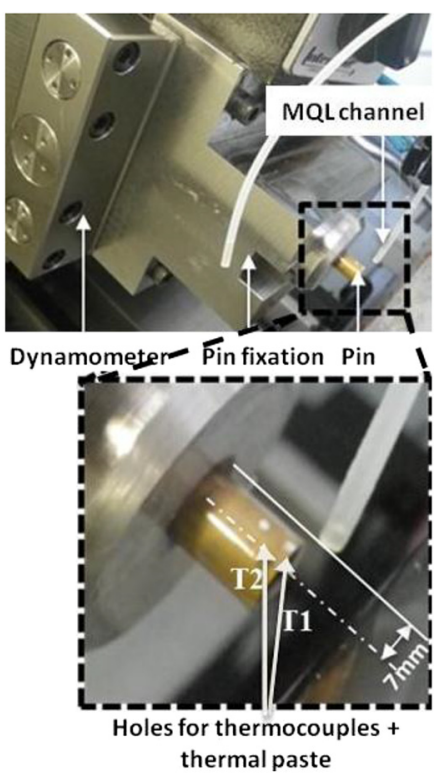

(b)
Fig. 1. (a) Illustration of the pin dimensions, the location of the holes to measure temperature and (b) the pin fixation details.

met in milling [21] through tribological study in order to understand the mechanisms explaining better results with the MQL flank face. Three different tribological pin-oncylinder tests were conducted: dry rubbing as a reference condition, MQL applied to front face rubbing and MQL applied to rear end rubbing. These tests were carried out with tungsten carbide pins grade 4240 from Sandvik Coromant supplier rubbing on X100CrMoV5 steel cylinder. The effects of lubrication configurations were analysed in terms of apparent coefficient of friction, adhesion area and heat flux transmitted to the pin.

\section{Experimental details}

In order to understand the friction mechanisms during face milling mould steel material (X100CrMoV5 type) when using MQL assistance, some tribological tests were performed on pin-on-cylinder technique. Due to the industrial context, pins were taken as the same as the carbide inserts and coating used in milling strategy from previous study [21].

\subsection{Materials and measurement}

A 4240 grade tungsten carbide hemispherical head pins with MTCVD $\mathrm{Al}_{2} \mathrm{O}_{3}$ coating were used in this study. All the pins had $40 \mathrm{~mm}$ length and $\varnothing 8 \mathrm{~mm}$ with a measured surface roughness of $0.2 \mu \mathrm{m}$. The surface roughness has been measured by a 3D profilometer using VEECO software. The hemispherical head had $17 \mathrm{~mm}$ radius (Fig. 1a).

All pins were achieved with two holes of $\varnothing 1 \mathrm{~mm}$ in order to measure temperature. The holes were located at $1 \mathrm{~mm}$ and $4 \mathrm{~mm}$ from the hemispherical head of the pin, as 
Table 1. Chemical composition of the X100CrMoV5.

\begin{tabular}{lllllllll}
\hline Chemical components & $\mathrm{Cr}$ & $\mathrm{Mo}$ & $\mathrm{V}$ & $\mathrm{C}$ & $\mathrm{Si}$ & $\mathrm{Mn}$ & $\mathrm{P}$ & $\mathrm{S}$ \\
\hline Containing (in wt.\%) & 5.3 & 1.1 & 0.20 & 1 & 0.3 & 0.70 & $\leq 0.025$ & $\leq 0.025$ \\
\hline
\end{tabular}

shown in Figure 1a. Temperatures were obtained with $\varnothing 0.13 \mathrm{~mm}$ K-type thermocouples connected to National Instruments NI USB-9162 equipment.

$\mathrm{X} 100 \mathrm{CrMoV} 5$ mould steel was used in this study as a cylindrical bar, with a cross section of $\varnothing 80 \mathrm{~mm}$ and a length of $500 \mathrm{~mm}$. Chemical composition of the cylindrical bar is given in Table 1. During the frictional test only $396 \mathrm{~mm}$ length was considered. After each frictional test, the cylindrical bar was longitudinally turned with a cutting depth of $0.1 \mathrm{~mm}$ in order to remove the plastically affected layer induced by the previous friction test and a new pin is fixed. Some alcohol was applied to remove any lubricant residue. The experimental test was set on digitally controlled Victor Vturn-A26 turning machine.

\subsection{Tribological test configurations}

Tribological studies were conducted in order to better understand the differences between the tool life results in milling machining configurations and to reproduce lubrication with MQL applied on rake face and MQL applied on flank face [21].

Three rubbing configurations were tested to reproduce three machining conditions under different lubrications:

- Dry rubbing, representing the dry machining condition. - MQL applied to front face rubbing (MQL FFR) which was the configuration representing milling with MQL on the rake face (Fig. 2a).

- MQL applied to rear end rubbing (MQL RER): this configuration represented milling with MQL on flank face (Fig. 2b).

All the tests were repeated at least three times.

In order to be in the same configuration as in machining when using MQL by inner canalizations on the tool holder [21], $\varnothing 1.6 \mathrm{~mm}$ nozzle is oriented at $30^{\circ}$ from the contact plan. The MQL nozzle was located also in the same distance $(7 \mathrm{~mm}$ as shown in Fig. 1b) and at the same side of the pin. The applied MQL regarding to milling conditions observed in the previous study (rake face or flank face) is governed by the rotating direction of the bar.

The oil mist was generated by an external mixing device (Lubrilean Digital Super device developed by SKF) supplied by 7 bar air pressure. Digital Super software can control the oil mist device to set the oil mist flow rate at $7 \mathrm{ml} \mathrm{h}^{-1}$ with about $27 \mathrm{NL} \min ^{-1}$ air flow rate. The selected oil was a synthetic ester PX5130 from the supplier Total. The apparent coefficient of friction and the temperature were measured during $396 \mathrm{~mm}$

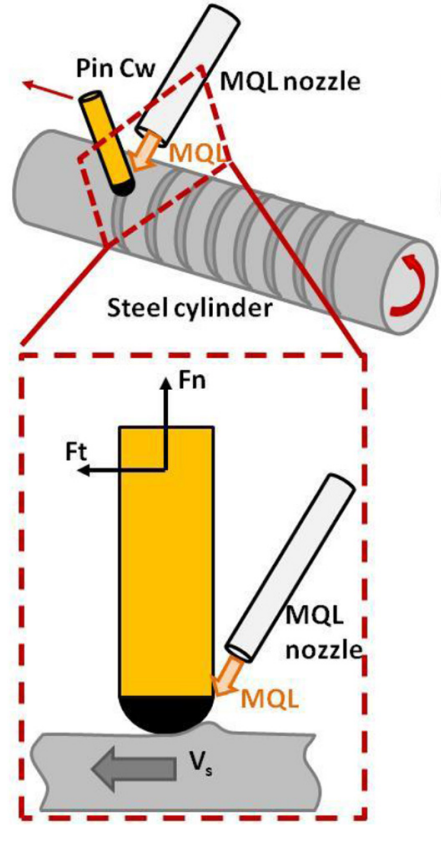

(a)

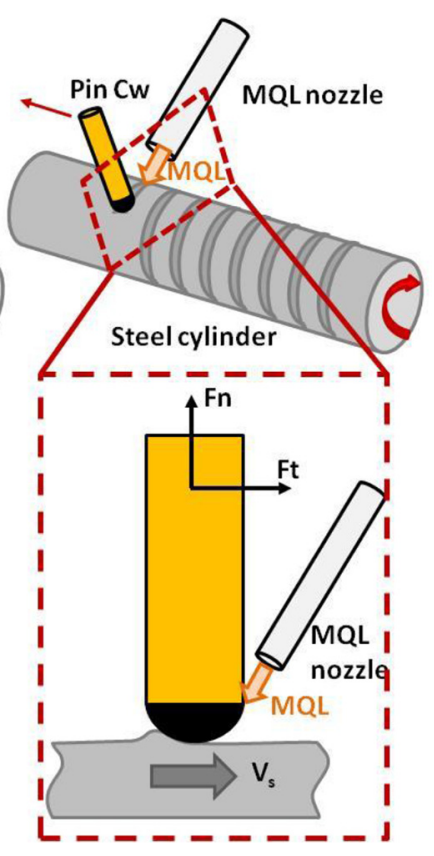

(b)
Fig. 2. Illustration of the MQL application configurations (a) in front face rubbing (by analogy with MQL rake face) and (b) in rear end rubbing (by analogy with MQL flank face).

long bar. The first quarter of test period was not considered until the temperature was stabilized. The contact forces were measured during the test using a KISTLER type 9129AA dynamometer.

The apparent coefficient of friction $\mu_{\text {app }}$ was calculated according to Coulomb's law (Eq. (1)).

$$
\mu_{\mathrm{app}}=\frac{F_{t}}{F_{n}}
$$

where $F_{t}$ and $F_{n}$ were respectively the tangential force and the normal force on the pin. This apparent coefficient of friction could be decomposed into an adhesion friction $\mu_{\text {adh }}$ and a plastic deformation friction $\mu_{\text {def }}$ [27] as shown in equation (2).

$$
\mu_{\text {app }}=\mu_{\text {adh }}+\mu_{\text {def }} .
$$

In order to be in the same milling machining configuration, a contact pressure of $1.7 \mathrm{GPa}$ was measured with the ratio between the cutting force and the contact surface [21]. 
In these tribological tests, the contact pressure has been evaluated by the Hertz theory described in equation (3) [28] as follows:

$$
P_{n}=\frac{3 \times F_{n}}{2 \times \pi \times a^{2}}
$$

where $P_{n}$ was the normal pressure of the contact (MPa), $F_{n}$ was the measured normal force applied to the pin $(\mathrm{N})$ and $a$ was the contact radius ( $\mathrm{mm})$.

This relationship allowed ascertaining of the normal force to apply [28]. The contact radius was estimated by Hertz's equation (Eq. (4)), as follows:

$$
a=\left\{\frac{3 \times \pi \times R_{1} \times R_{2}}{4 \times\left(R_{1}+R_{2}\right)}\left[\frac{1-v_{1}^{2}}{\pi \times E_{1}}+\frac{1-v_{2}^{2}}{\pi \times E_{2}}\right]\right\}^{1 / 3},
$$

where $R_{i}, E_{i}$ and $v_{i}$ were, respectively, the radius (mm), the Young modulus (MPa) and the Poisson coefficient of the considered materials. The summary of these mechanical properties is shown in Table 2. Mechanical properties of the pin are nearly three times higher than the cylinder, which led to not consider the properties of the coating in this study.

Table 2. Mechanical and geometrical properties of contact materials.

\begin{tabular}{llll}
\hline & $\begin{array}{l}\text { Young } \\
\text { modulus } \\
E_{i}(\mathrm{GPa})\end{array}$ & $\begin{array}{l}\text { Poisson's } \\
\text { ratio } v_{i}\end{array}$ & $\begin{array}{l}\text { Radius } \\
R_{i}(\mathrm{~mm})\end{array}$ \\
\hline Pin $(1)$ & 580 & 0.24 & 17 \\
Cylinder $(2)$ & 210 & 0.3 & 40 \\
\hline
\end{tabular}

Adhesion area, apparent coefficient of friction and dissipated heat flux in the pin were measured for each test, in order to understand the physical phenomena of the applied MQL.

The rubbing velocity was taken as $135 \mathrm{~m} \mathrm{~min}^{-1}$ with a pin rate of $0.4 \mathrm{~mm} \mathrm{tr}^{-1}$ in order to be in the same machining conditions and to get freshly removed material. A $125 \mathrm{~N}$ normal force was applied from the pin to the bar in order to be in the same contact pressure than the milling conditions, up to $1.7 \mathrm{GPa}[21]$.

Figure $3 \mathrm{a}-\mathrm{c}$ showed the evolution of the apparent coefficient of friction, the adhesion area and the temperature gradient, respectively, for the three lubrication conditions (dry, MQL FFR and MQL RER). Normal and tangential forces were measured during rubbing. These rubbing forces were considered in order to calculate the apparent coefficients of friction (Fig. 3a). Error bars highlighted consistent and good level of repeatability of results. The application of MQL FFR reduced the apparent coefficient of friction by up to $72 \%$ compared to dry rubbing. With the application of MQL RER, coefficient of friction was reduced by up to $42 \%$ compared to MQL FFR.

The size of adhesion area (Fig. 3b) was measured by image analysis using an optical microscope Keyence VHX500 (top of Fig. 4). This adhesion area was bigger than the theoretical contact area and was defined by the friction of material generated by a strong plastic strain from the material to the pin. Outlines were drawn by image posttreatment in order to predict the adhesion area. Error bars highlighted similar and repetitive results. Adhesion area was reduced by up to $65 \%$ with the application of MQL FFR compared to dry rubbing.

During these frictional tests, temperatures were measured with two $\varnothing 0.13 \mathrm{~mm}$ K-type thermocouples set into the pins as shown previously in Figure 1. Temperature

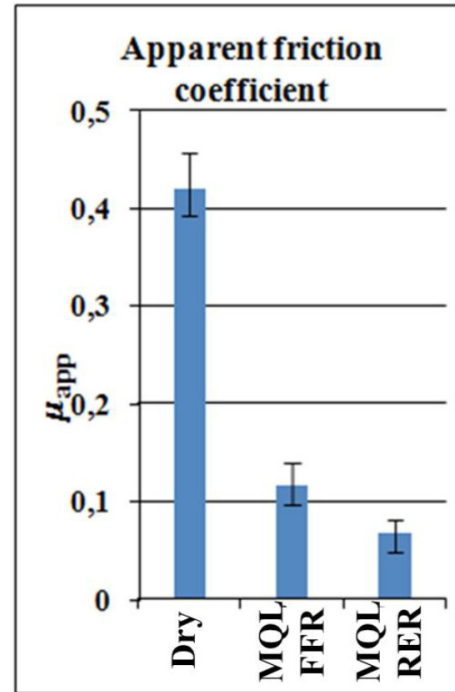

(a)

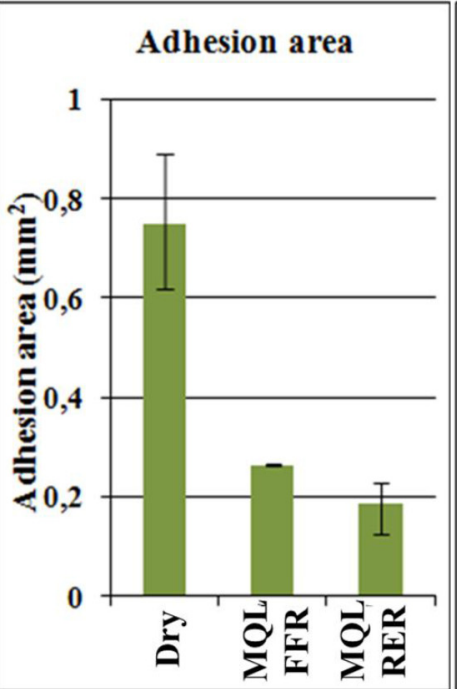

(b)

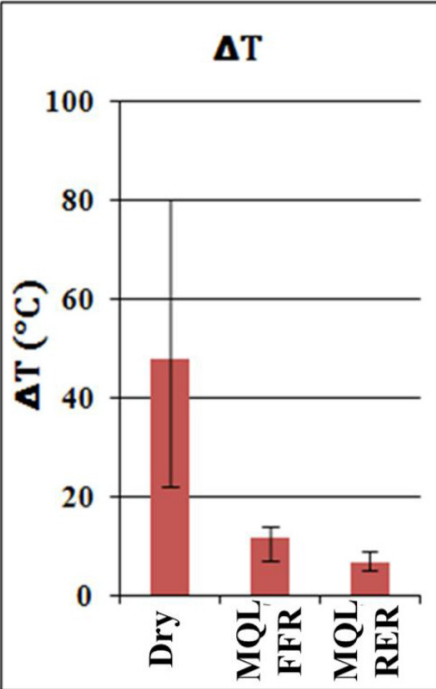

(c)

Fig. 3. Comparison between dry rubbing, MQL front face rubbing (MQL rake face) and MQL rear end rubbing (MQL flank face) for (a) apparent coefficient of friction, (b) adhesion area and (c) temperature variation between the two holes in the pin. 

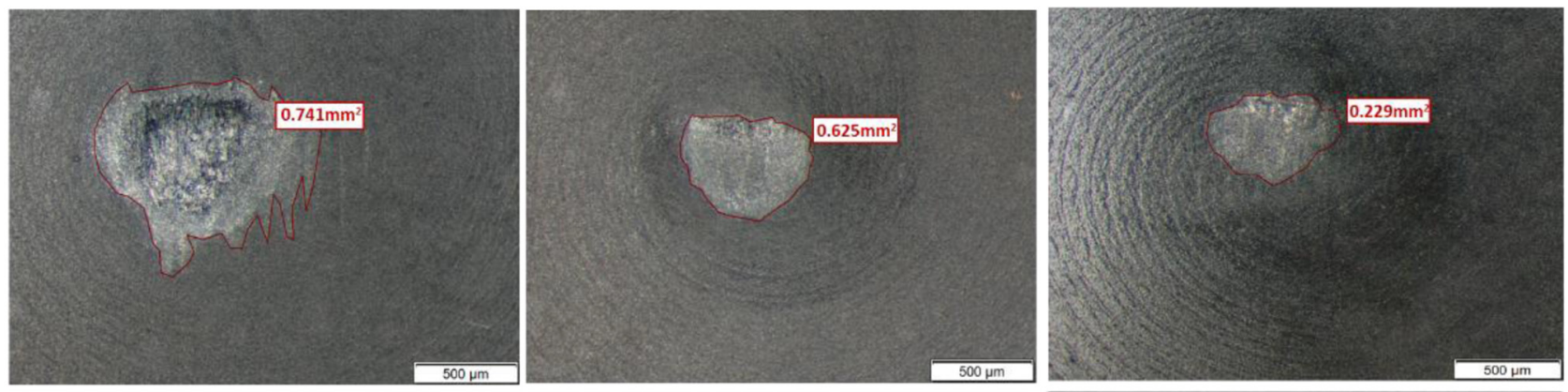

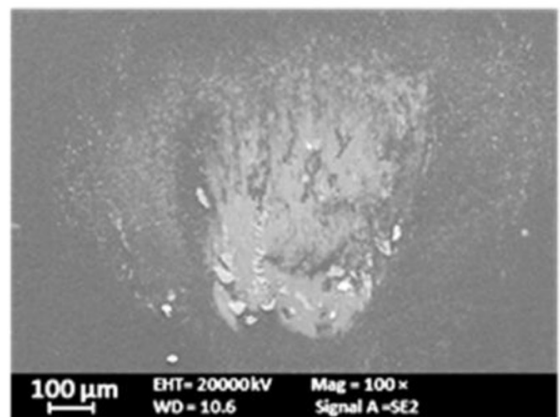

(a)

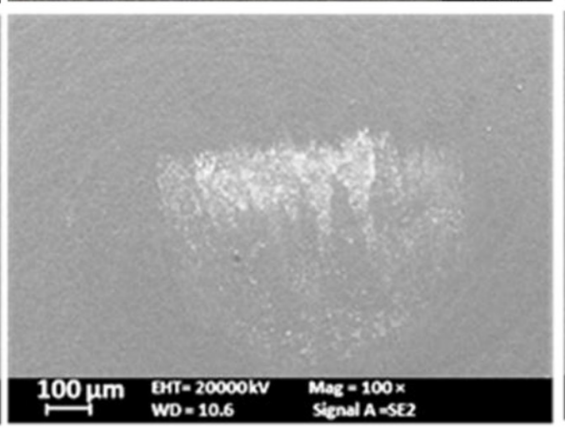

(b)

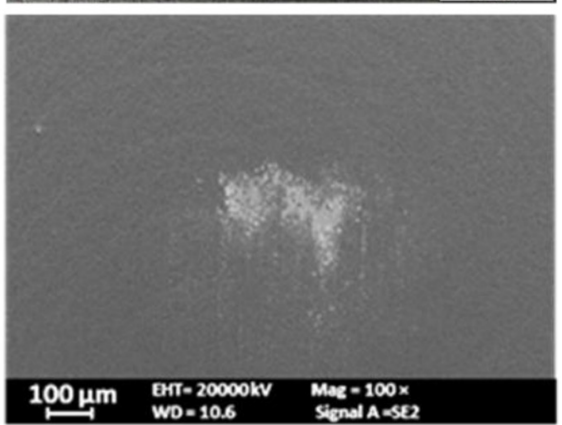

(c)

Fig. 4. Optical microscope at the top and SEM analysis at the bottom of the adhesion surfaces on the pin for (a) dry, (b) MQL FFR and (c) MQL RER conditions.

gradient measurements $(\Delta T)$ were conducted between the two measurement points in the pins. Figure $3 \mathrm{c}$ showed the same trend observed on the apparent coefficients of friction and adhesion area. Error bars were small and led to repetitive results regarding the different temperature gradients with MQL. But in dry condition error bar was very high, leading to no repetitive results. Several factors could influence the variation in gradient temperature such as sticking phenomena, pin wear or vibration.

\section{Discussion}

As expected, applying MQL had significant benefits in terms of friction, temperature and adhesion, regarding to dry condition. Adhesion area of pins for each configuration were analysed under JEOL JSM-6480 scanning electron microscope (bottom of Fig. 4), as a complement of optical microscope analysis (top of Fig. 4). SEM analyses highlighted the build-up phenomenon in the adhesion area with brightness adjustment. Results showed that there was no significant chipping adhesion when MQL was used (Fig. 4b and c), when compared to the dry condition (Fig. 4a). MQL application reduced the severity of the contact. Rubbing tests with MQL RER decreased the adhesion area up to $29.65 \%$ when compared to MQL FFR. The decrease of adhesion area resulted from a better oil penetration at pin-workpiece interface.

Adhesion area had a direct influence on temperature and more specifically on the heat flux dissipated on pins $\left(\Phi_{\text {pin }}\right)$. From the temperature gradient $(\Delta \mathrm{T})$ measured in the last paragraph, dissipated heat flux was determined by
Table 3. Summary of results measured and calculated for the three rubbing environments.

\begin{tabular}{llll}
\hline & Dry & MQL FFR & MQL RER \\
\hline$\Delta T\left({ }^{\circ} \mathrm{C}\right)$ & 47.60 & 11.66 & 6.67 \\
$\lambda_{C w, 1000^{\circ} \mathrm{C}}$ & & 89.89 & \\
$\left(\mathrm{~W} \cdot \mathrm{m}^{-1} \cdot \mathrm{K}^{-1}\right)$ & & & \\
$S_{\text {pin }}\left(\mathrm{m}^{2}\right)$ & & $5.03 \times 10^{-5}$ & \\
$\phi_{\text {pin }}(\mathrm{W})$ & 53.77 & 13.17 & 7.53 \\
\hline
\end{tabular}

Fourier's law equation (Eq. (5)), as follows:

$$
\phi_{\text {pin }}=\lambda_{C w .100^{\circ} \mathrm{C}} \times S_{\text {pin }} \times \frac{(\Delta T)}{d x},
$$

where $S_{\text {pin }}$ was the pin cross-section $\left(\mathrm{m}^{2}\right), d x$ was the distance between the two temperature measurement points on the pin $(\mathrm{m})$ and $\lambda_{C w .100}{ }^{\circ} \mathrm{C}$ was the thermal conductivity of the grade of tungsten carbide at $100^{\circ} \mathrm{C}\left(\mathrm{W} \mathrm{m}^{-1} \mathrm{~K}^{-1}\right)$.

The physical and geometrical characteristics and the dissipated heat flux results were given in Table 3.

Heat flux in the pin was higher with dry rubbing condition than using MQL, reaching approximately $54 \mathrm{~W}$. When using MQL, heat flow was reduced by a factor of about 4 and 7 with MQL FFR and MQL RER, respectively, when compared to dry test. A very significant difference between both applied MQL was observed. The dissipated heat flux when MQL was applied in front face rubbing was about twice as high as that with MQL applied in rear end rubbing. 


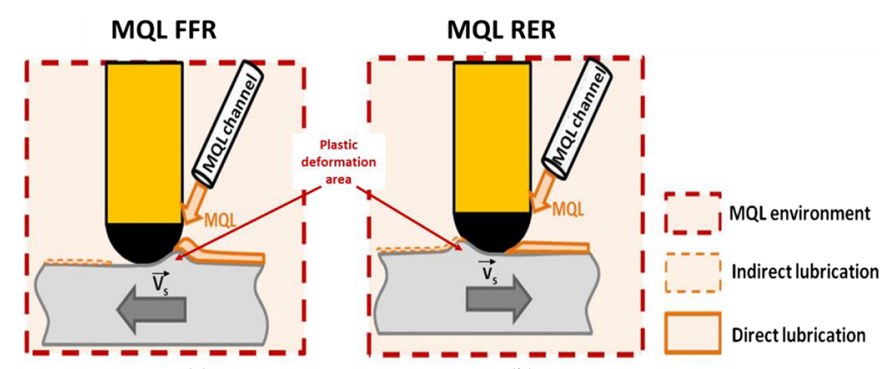

(a)

Fig. 5. Identifying lubricated zones during the pin-cylinder tests with MQL.

Figure 5 showed exactly the physical phenomena occurred under different lubrications. During MQL rubbing tests, an MQL environment was created around the cylinder and the pin which are indirectly lubricating. This indicated that some oil mist was sprayed around the pin on the cylinder and some amount of oil was kept on the roughness of the cylinder. With MQL FFR, the surface that will be removed was targeted and directly lubricated by the MQL channel. However, the surface that has just been generated was faced on MQL environment, as shown in Figure 5a. Moreover, the created plastic deformation prevents oil from penetrating or lead to a partial penetration to the frictional surface (presence of oil on roughness of the cylinder). On the other hand, with MQL RER, the surface that will be removed is constantly indirectly lubricated, because of the MQL environment defined in Figure 5. Moreover, the surface that has just been generated was targeted with an MQL channel and instantly lubricated. Hence, MQL RER provided instantly maximal lubrication, which drastically reduced heat flux transmitted to the pin and the coefficient of friction. With regards to the numerical studies of Bonnet et al. and Rech et al., the maximum stress was located in front face of the rubbing contact along the symmetry axis $[23,29]$. The contact pressure in FFR is about $40 \%$ higher compared to RER [23,29]. Then, micro-lubricant FFR has some difficulty to penetrate pin-workpiece interface. On the other hand, by lubricating rear end the rubbing supporting lower pressures will lead to a better penetration of the lubricant, reducing then adhesion area.

By analogy with milling machining [21], MQL applied on rake face was not as efficient as MQL applied on flank face. Because of the extreme contact in tool-chip interface [30], oil mist did not penetrate as much as required. Better results were ensured with MQL applied on flank face because of the ability of the oil mist to penetrate the tool workpiece interface. MQL was an effective alternative to dry rubbing, more specifically MQL applied on rear end rubbing (or flank face).

\section{Conclusions}

Pin-on-cylinder tests have been performed with 4240 grade tungsten carbide hemispherical head pin with MTCVD $\mathrm{Al}_{2} \mathrm{O}_{3}$ coating on X100CrMoV5 cylinder.

MQL applied on front face rubbing and MQL applied on rear end rubbing conditions were performed during these tests by analogy with previous results studied in milling machining (MQL applied on flank face and MQL applied on rake face). Dry tests were conducted as reference. Apparent coefficient of friction, adhesion area and temperature gradient were analysed. As expected, the investigation indicated that the application of $\mathrm{MQL}$ offered better results than with dry condition in terms of adhesion area and generated heat flux. The applied MQL at pin rear end rubbing reduced coefficient of friction by up to $42 \%$ compared to MQL front face rubbing. Moreover, rubbing tests with MQL rear end rubbing decreased the adhesion area up to $29.65 \%$ when compared to MQL front face rubbing, thanks to a better oil penetration at pin-workpiece interface. Finally, heat flow was reduced to almost half with MQL rear end rubbing compared to front face rubbing. These pin-on-cylinder test observations led to better understand the tribological phenomena occurring in machining. MQL applied on front face rubbing (MQL applied on rake face by analogy with milling machining) did not penetrate as much as required at tool workpiece interface. The generated plastic deformation area, similar to a chip by analogy with milling machining, prevented the oil mist penetration. On the other side, with MQL applied to rear end rubbing, the lubricated zone supported lower pressures enabling the fluid to penetrate the pin-workpiece interface. Similarly, with machining, higher pressures are located on the insert rake face rather than flank face [30]. Then, oil mist penetrates more effectively the insert-workpiece interface rather than insert-chip interface.

This study successfully explained the results obtained with MQL flank face (in the previous study [21]) compared to MQL rake face in terms of tool life and roughness of the machined surface.

In future works, same studies could be conducted with different coating and oil properties on different materials to see if the results show the same trend. Thus, different machining conditions under MQL applied on flank face on different materials could be extended.

The authors would like to thank the cutting tool research centre operators (CEROC, France), for their support in machining and tribological tests and also gratefully acknowledge SANDVIKCOROMANT for pins supplies.

\section{References}

[1] W.A. Khan, N.M. Hoang, B. Tai, W.N.P. Hung, Throughtool minimum quantity lubrication and effect on machinability, J. Manuf. Process. 34, 750-757 (2018)

[2] R.R. Srikant, M.M.S. Prasad, M. Amrita, V. Sitaramaraju, Nanofluids as a potential solution for Minimum Quantity Lubrication: A review, J. Eng. Manuf. 228, 3-20 (2014)

[3] N. Banerjee, A. Sharma, Improving machining performance of Ti-6Al-4V through multi-point minimum quantity lubrication method, Proc. Inst. Mech. Eng. Part B J. Eng. Manuf. 233, 321-336 (2018) 
[4] S. Zhang, J.F. Li, Y.W. Wang, Tool life and cutting forces in end milling Inconel 718 under dry and minimum quantity cooling lubrication cutting conditions, J. Clean. Prod. 32, 81-87 (2012)

[5] E.A. Rahim, H. Sasahara, Investigation of tool wear and surface integrity on MQL machining of Ti-6AL-4V using biodegradable oil, Proc. Inst. Mech. Eng. Part B J. Eng. Manuf. 225, 1505-1511 (2011)

[6] A.K. Sharma, A.K. Tiwari, A.R. Dixit, Effects of minimum quantity lubrication (MQL) in machining processes using conventional and nanofluid based cutting fluids: A review, J. Clean. Prod. 127, 1-18 (2016)

[7] A. Duchosal, S. Werda, R. Serra, R. Leroy, H. Hamdi, Numerical modeling and experimental measurement of MQL im- pingement over an insert in a milling tool with inner channels, Int. J. Mach. Tools Manuf. 94, 37-47 (2015)

[8] R.P. Zeilmann, W.L. Weingaertner, Analysis of temperature during drilling of Ti6Al4V with minimal quantity of lubricant, J. Mater. Process. Technol. 179, 124-127 (2006)

[9] T. Aoyama, Development of a mixture supply system for machining with minimal quantity lubrication, CIRP Ann. Manuf. Technol. 51, 289-292 (2002)

[10] A. Duchosal, R. Serra, R. Leroy, Numerical study of the inner canalization geometry optimization in a milling tool used in micro quantity lubrication, Mech. Ind. 15, 435-442 (2014)

[11] L.N. López de Lacalle, C. Angulo, A. Lamikiz, J.A. Sánchez, Experimental and numerical investigation of the effect of spray cutting fluids in high speed milling, J. Mater. Process. Technol. 172, 11-15 (2006)

[12] T. Childs, K. Maekawa, T. Obikawa, Y. Yamane, Metal Machining Theory and Applications, John Wiley \& Sons, New York, 2000

[13] J.A. Bailey, Friction in metal machining-Mechanical aspects, Wear 31, 243-275 (1975)

[14] C. Claudin, a. Mondelin, J. Rech, G. Fromentin, Effects of a straight oil on friction at the tool-workmaterial interface in machining, Int. J. Mach. Tools Manuf. 50, 681-688 (2010)

[15] S. Masoudi, A. Vafadar, M. Hadad, F. Jafarian, Experimental investigation into the effects of nozzle position, workpiece hardness, and tool type in MQL turning of AISI 1045 steel, Mater. Manuf. Process. 33, 1011-1019 (2018)

[16] S. Ekinovic, H. Prcanovic, E. Begovic, Investigation of influence of MQL machining parameters on cutting forces during MQL turning of carbon steel St52-3, Procedia Eng. 132, 608-614 (2015)

[17] A.E. Diniz, R. Micaroni, Influence of the direction and flow rate of the cutting fluid on tool life in turning process of AISI 1045 steel, Int. J. Mach. Tools Manuf. 47, 247-254 (2007)
[18] A. Attanasio, M. Gelfi, C. Giardini, C. Remino, Minimal quantity lubrication in turning: effect on tool wear, Wear 260, 333-338 (2006)

[19] M. Hadad, B. Sadeghi, Minimum quantity lubrication-MQL turning of AISI 4140 steel alloy, J. Clean. Prod. 54, 332-343 (2013)

[20] M. Ozawa, A. Hosokawa, R. Tanaka, T. Furumoto, T. Ueda, ozawa2009, J. Jpn. Soc. Abras. Technol. 53, 88-93 (2009)

[21] S. Werda, A. Duchosal, G. Le Quilliec, A. Morandeau, R. Leroy, Minimum quantity lubrication advantages when applied to insert flank face in milling, Int. J. Adv. Manuf. Technol. 92, 2391-2399 (2017)

[22] F. Zemzemi, J. Rech, W. Ben Salem, A. Dogui, P. Kapsa, Identification of a friction model at tool/chip/workpiece interfaces in dry machining of AISI4142 treated steels, J. Mater. Process. Technol. 209, 3978-3990 (2009)

[23] C. Bonnet et al., Identification of a friction model Application to the context of dry cutting of an AISI 316L austenitic stainless steel with a TiN coated carbide tool, Int. J. Mach. Tools Manuf. 48, 1211-1223 (2008)

[24] F. Zemzemi, W. Bensalem, J. Rech, A. Dogui, P. Kapsa, New tribometer designed for the characterisation of the friction properties at the tool/chip/workpiece interfaces in machining, Tribotest 14, 11-25 (2008)

[25] P. Faverjon, J. Rech, R. Leroy, M. Orset, Influence of MQL on friction coefficient and workmaterial adhesion during machining of cast aluminum with various cutting tool substrates made of PCD, HSS, and carbides, J. Tribol. 135, 4 (2012)

[26] F. Cabanettes, J. Rolland, F. Dumont, J. Rech, Z. Dimkovski, Influence of minimum quantity lubrication on friction characterizing tool-aluminum alloy contact, J. Tribol. 138, 021107 (2016)

[27] J.M. Challen, P.L.B. Oxley, An explanation of the different regimes of friction and wear using asperity deformation models, Wear 53, 229-243 (1979)

[28] G.M. Hamilton, Explicit equations for the stresses beneath a sliding spherical contact, Proc. Inst. Mech. Eng. 197C, 53-59 (1983)

[29] J. Rech, C. Claudin, E. D'Eramo, Identification of a friction model-application to the context of dry cutting of an AISI 1045 annealed steel with a TiN-coated carbide tool, Tribol. Int. 42, 738-744 (2009)

[30] C. Bonnet, F. Valiorgue, J. Rech, H. Hamdi, Improvement of the numerical modeling in orthogonal dry cutting of an AISI $316 \mathrm{~L}$ stainless steel by the introduction of a new friction model, CIRP J. Manuf. Sci. Technol. 1, 114-118 (2008)

Cite this article as: S. Werda, A. Duchosal, G. Le Quilliec, A. Morandeau, R. Leroy, Effect of minimum quantity lubrication strategies on tribological study of simulated machining operation, Mechanics \& Industry 20, 624 (2019) 